\title{
Who fails to return within 30 days after being tested positive for HIV/STI in a free testing centre?
}

Camille Rolland ${ }^{1,2^{*}}$ (D) Elise de La Rochebrochard ${ }^{3,4}$, Prescillia Piron ${ }^{1,2}$, Marc Shelly ${ }^{1,2}$, Christophe Segouin ${ }^{1,2}$ and Pénélope Troude ${ }^{1,3}$

\begin{abstract}
Background: Some patients who test positive for sexually transmitted infections (STIs) fail to return for results and treatment. To target improvement actions, we need to find out who these patients are. This study aimed to explore factors associated with failure to return within 30 days (FTR30) after testing among patients with positive results in a free STI testing centre in Paris.

Methods: All patients with at least one positive result between October 2016 and May 2017 and who completed a self-administered questionnaire were included in this cross-sectional study $(n=214)$. The questionnaire included sociodemographic factors, sexual behaviour and history of testing. Factors associated with FTR30 were assessed using logistic regression models.

Results: More than two-thirds of patients were men (72\%), and the median age of patients was 27 years. Most patients were born in metropolitan France (56\%) or in sub-Saharan Africa (22\%). Men who had sex with men represented $36 \%$ of the study population. The FTR30 rate was 14\% (95\% Cl [10-19\%]). In multivariate analysis, previous HIV testing in younger persons (aOR: 3.36, 95\% CI [1.27-8.84]), being accompanied by another person at the pretest consultation (aOR: $3.45,95 \% \mathrm{Cl}[1.36-8.91]$ ), and lower self-perceived risk of HIV infection (aOR: 2.79, 95\% $\mathrm{Cl}$ [1.07-7.30]) were associated with a higher FTR30. Testing for chlamydia/gonorrhoea without presumptive treatment was associated with a lower FTR30 (aOR: 0.21, 95\% Cl [0.07-0.59]).

Conclusions: These factors that affect failure to return are related to the patient's representations and involvement in the STI screening process. Increasing health literacy and patient empowerment could help to decrease failure to return after being tested positive for HIV/STI.
\end{abstract}

Trial registration: Not applicable.

Keywords: HIV infection, STI, Screening, Preventive health, Sexual risk behaviours, Patient dropouts

\footnotetext{
* Correspondence: rollandcamille@ymail.com

'Department of Public Health, University Hospital

Saint-Louis-Lariboisière-Fernand-Widal, AP-HP, 200 rue du

Faubourg-Saint-Denis, F-75475, Paris Cedex 10, Paris, France

${ }^{2}$ Free Sexual Health Centre, University Hospital

Saint-Louis-Lariboisière-Fernand-Widal, AP-HP, Paris, France

Full list of author information is available at the end of the article
}

(C) The Author(s). 2020 Open Access This article is licensed under a Creative Commons Attribution 4.0 International License, which permits use, sharing, adaptation, distribution and reproduction in any medium or format, as long as you give appropriate credit to the original author(s) and the source, provide a link to the Creative Commons licence, and indicate if changes were made. The images or other third party material in this article are included in the article's Creative Commons licence, unless indicated otherwise in a credit line to the material. If material is not included in the article's Creative Commons licence and your intended use is not permitted by statutory regulation or exceeds the permitted use, you will need to obtain permission directly from the copyright holder. To view a copy of this licence, visit http://creativecommons.org/licenses/by/4.0/. The Creative Commons Public Domain Dedication waiver (http://creativecommons.org/publicdomain/zero/1.0/) applies to the data made available in this article, unless otherwise stated in a credit line to the data. 


\section{Introduction}

Sexually transmitted infections (STIs) are a major challenge in public health as nearly one million people become infected every day in the world with chlamydia, gonorrhoea, syphilis or trichomoniasis [1]. To decrease the spread of STIs, the World Health Organization (WHO) recommends focusing particularly on screening, counselling and early treatment [2]. In France, these missions are carried out by the national network of free testing centres for sexually transmitted infections. However, a proportion of patients who are tested for STIs do not return for their results. Some studies have suggested that the fear of a positive HIV result, stigmatization and discrimination may explain failure to return for test results [3-5]. For patients screened positive, failure to return (FTR) means that they are not aware of their positive result. Consequently, they cannot begin early treatment and receive additional information.

Some studies that explored FTR after HIV/STI tests reported rates that ranged from 3 to $30 \%$ [6-11]. Results concerning factors associated with FTR appeared mixed but suggested that FTR is affected by both individual factors and contextual factors (access to testing, social stigma ...) [12]. Most previous studies on FTR were conducted among the total patient population whatever the result of screening. However, some studies suggested that patients with a positive test are less likely to return than patients with negative results [12]. Moreover, none of the previous studies took into account full STI screening (HIV, HBV, HCV, syphilis, chlamydia and gonorrhoea). The recent introduction of pre-exposure prophylaxis (PrEP) for HIV raises concerns about STI incidence and the possible decline in condom use [13]. Besides, use of rapid point-of-care testing (POCT) for HIV may increase the FTR for other tested STIs [9]. In view of these new prevention strategies, FTR is now a concern for all STIs and not only for HIV.

In order to decrease FTR for patients who screen positive, a first approach would be to improve understanding of patient-related factors that influence FTR and to develop improvement actions for these high-risk patients $[8,12,14]$. Another approach consists in developing new ways of contacting patients with their results, including SMS notification $[10,11,15]$. The first international trials showed that SMS notification is associated with a shorter time before starting treatment [10, 11]. Since August 2016, SMS notification is being tested in a free STI testing centre in Paris [16]. If at least one result is positive, the SMS invites the patient to return to the centre to obtain their results and receive appropriate guidance and/or treatment. This procedure is in agreement with national and European guidelines as positive results are still always delivered in person by a physician [17].
The objective of this study was to explore factors associated with failure to return within 30 days after testing among persons with at least one positive result in a free STI testing centre in Paris, France, which offers SMS notification.

\section{Materials and methods \\ Setting}

The study was conducted in a free STI testing centre in Fernand Widal Hospital in northern Paris. Care is entirely free of charge for all patients, even if they have no health insurance coverage. The tests performed include HIV, HBV, HCV, syphilis, gonorrhoea and chlamydia (urinary, vaginal, oropharyngeal and anorectal tests). HIV, hepatitis and syphilis are screened by serology. For gonorrhoea and chlamydia screening, self-swabbing is done by patients. Before the consultation, a selfadministered questionnaire was proposed to all new patients visiting the centre and was completed in the waiting room. This questionnaire was included in the patient's medical file and helped the doctor to direct the consultation according to the patient's answers. However, only patients familiar with written French were able to complete the questionnaire. During pre-test counselling, the doctor evaluates each patient's risktaking behaviour and prescribes appropriate screening tests. Moreover, according to national recommendations for chlamydia/gonorrhoea, treatment is systematically started prior to results (presumptive treatment) when symptoms are strongly suggestive of chlamydia/gonorrhoea infections. Results are available approximately 1 week later. Patients can choose to be tested anonymously or not. Whether the patient chooses to remain anonymous for screening or not, he or she is given an anonymity number ensuring confidentiality throughout the process. The text messaging programme is proposed to patients by the reception agent who explains the programme with the help of a leaflet: 1) if all results are negative, the patient is informed by SMS and he/she does not need to return to the testing centre; 2) if at least one result is positive, the SMS invites the patient to come back to the centre to obtain the results. Up to three messages are sent if the patient fails to return. The SMS programme has been developed to respect medical confidentiality and is presented in detail elsewhere [16].

\section{Study population}

From October 2016 to May 2017, 2611 patients visited the free STI testing centre. During the 8 months of the study period, 2315 patients underwent STI testing, 219 came for post-exposure treatment and 77 came only for information with no testing. Among the 2315 patients who underwent STI testing, 266 (11\%) patients had at least one positive test. Of these 266 positive patients, 
214 patients filled in the self-administered questionnaire (participation rate $80 \%$ ) and were included in this crosssectional study.

\section{Data sources}

Data were collected from two complementary sources: the consultation database and the self-administered questionnaire.

The following data were routinely entered in the consultation database: date of first visit, anonymous testing, participation in the text messaging programme, STIs tested, provision of presumptive treatment for chlamydia or gonorrhoea or not, date of return, and results of the screening tests performed.

The questionnaire included sociodemographic factors: age, gender (woman, man, transgender), place of residence, place of birth, educational level and health insurance coverage, sexual behaviour and history (including sexual orientation and occasional and/or regular sex partners), previous HIV testing and factors related to the visit to the centre (who suggested testing, accompaniment by another person at the consultation, reason for attending indicated by one or several items that can be ticked among a list of 14 reasons), self-perceived risk of HIV infection (the patient perceived himself/herself at a higher risk of infection compared with the general population, equal risk, lower or no risk).

\section{Outcome}

In the literature, the time period used to define FTR varied between 1 month and 1 year $[4,9,12,14]$. However, all studies showed that most patients returned for results between 7 days and 21 days after testing $[6,8,10,18$, 19]. Thus, FTR at 30 days is a relevant indicator and was used in this study.

\section{Factors analysed}

Only 10 patients were aged over 25 years and had no previous HIV testing. Age and previous HIV testing were therefore combined in one variable with three categories: patients aged 25 years or older, patients under 25 years with no previous HIV testing and patients under 25 years with previous HIV testing.

In our study population, there were no transgender persons and only 7 patients were women who had sex with women. Gender and sexual orientation were therefore combined in a single variable with three categories: men who had sex with men (including bisexual men), heterosexual men, and women.

To explore both the potential role of self-swabbing and of presumptive treatment in FTR (patients may have thought they did not need to return because they had already been treated), data on testing for chlamydia/gonorrhoea infections and provision of presumptive treatment at the pre-test visit were combined in a single variable: not tested for chlamydia and gonorrhoea, tested without provision of presumptive treatment, tested with provision of presumptive treatment.

Consultation for risk-taking was based on the reason for attending given by patients in the questionnaire. We considered that the consultation was for risk-taking if the patient ticked at least one item among the 11 reasons corresponding to a risk (unprotected sexual intercourse, clinical signs of STI, HIV-positive sex partner, sex with sex worker ...). The consultation was not for risk-taking if the patient reported that he/she wanted only information or reassurance, or if the patient wanted to be tested before stopping condom use with his/her regular partner.

Self-perceived risk of HIV infection was summarised into a binary variable: self-perceived risk higher or equal to the general population vs lower or no risk.

\section{Statistical methods}

Patient characteristics were compared according to FTR30 using the $\chi^{2}$ test or Fisher's test. Univariate and multivariate analyses were conducted to assess factors associated with FTR30 using logistic regression models. Considering the limited number of events in our study, we adopted a parsimonious methodology using a stepwise backward selection with a threshold of 0.2 for removal from the model. Association was considered as statistically significant when $p<0.05$. Statistical analyses were performed using STATA/SE 11.0 (Stata Corporation, College Station, TX, USA).

\section{Results}

The characteristics of the study population are presented in Table 1 . The median age of patients was 27 years and more than two-thirds were men (72\%). Men who had sex with men (MSM) represented 36\% of the study population. More than half of the participants lived in Paris. Most patients were born in metropolitan France (56\%) or in sub-Saharan Africa (22\%), and more than three-quarters of the population had completed education beyond high school (79\%). Most patients had already been tested for HIV (84\%), less than half declared that they had occasional sex partners (43\%) but two-thirds declared that they came for screening because of risk-taking (67\%). The majority of patients preferred to remain anonymous (64\%) but agreed to be notified by SMS after screening (72\%).

Patients were screened for a median of 5 STIs among the 6 available in the centre (Q1-Q3 [4-6]). Most patients were positive for only one STI (91\%), 18 patients were positive for two (8\%) and one patient for three. Distribution of positive screenings is presented in Table 2. Of the 214 patients tested positive for at least 
Table 1 Description of the study population $(n=214)$

\begin{tabular}{ll}
\hline Characteristics & $\mathbf{n}$ \\
\hline Age* (years) and previous HIV testing $^{*}$ & 132 \\
$\geq 25$ & 25 \\
$<25$ and no previous & \\
HIV testing & 57 \\
$<25$ and previous HIV testing & \\
Sexual orientation & 76 \\
Men who had sex with & \\
men (MSM) & 77 \\
Heterosexual men & 61 \\
Women &
\end{tabular}

Place of residence

Paris

Outside Paris

\section{Birthplace}

Metropolitan France

Sub-Saharan Africa

Overseas France or abroad

Level of education

High school graduate

Not a high school graduate

Health insurance coverage

Statutory health insurance

State assistance

None

Occasional partners

No

Yes

\section{Self-perceived risk of HIV infection}

Equal or greater than other people

Less than other people or no risk

Consultation for risk-taking

No

Yes

Accompanied by another person

No

Yes

Anonymous testing

Yes

No

Participation in SMS programme

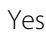

No

Chlamydia/gonorrhoea testing

Not tested for chlamydia/ gonorrhoea
Table 1 Description of the study population $(n=214)$

(Continued)

\begin{tabular}{lll}
\hline Characteristics & $\mathbf{n}$ & $\%$ \\
\hline $\begin{array}{l}\text { Chlamydia/gonorrhoea } \\
\text { testing with presumptive }\end{array}$ & 19 & 9 \\
treatment & & \\
$\begin{array}{l}\text { Chlamydia/gonorrhoea testing } \\
\text { without presumptive treatment }\end{array}$ & 160 & 75 \\
\hline *Category $\geq 25$ includes patients aged 25 to 70 years; category $<25$ includes \\
patients aged 18 to 24 years
\end{tabular}

one STI and included in the study, $14 \%(n=30)$ failed to return within 30 days after testing (95\% CI [10-19\%]). All patients who tested positive for HIV $(n=10)$ returned within 30 days after testing. However, over a quarter of patients who tested positive for HBV failed to return for their results $(8 / 29)$. Of the 30 patients who failed to return within 30 days, 7 returned between 31 and 60 days. The 60-day FTR rate was $11 \%$ (95\% CI [7$16 \%])$. Overall, the median interval before returning for results was 8 days (Q1-Q3 [6-13]).

Table 3 presents factors associated with FTR30. In univariate analysis, FTR30 appeared higher for patients younger than 25 years old who had previous HIV testing (23\%) compared with patients under 25 years old with no previous HIV testing (4\%). The FTR30 rate was higher for patients who had a lower self-perceived risk 80 of HIV infection (20\%) than for those who saw them11 selves as being at higher risk $(7 \%$, chi2 $p=0.008)$. The $9 \quad$ FTR30 rate was $24 \%$ for patients who were accompanied versus $11 \%$ for patients who came to the centre alone (chi2 $p=0.03$ ). Patients who were tested for chlamydia/ gonorrhoea and were given presumptive treatment were twice as likely to fail to return for their results as patients who were tested without provision of presumptive treatment ( $21 \%$ vs. $10 \%)$. The FTR30 rate reached $29 \%$ for patients not tested for chlamydia/gonorrhoea. Of the

Table 2 Distribution of positive screenings and failure to return for results $(n=214)$

\begin{tabular}{llll}
\hline Positive screenings & $\mathbf{n}$ & $\%$ & FTR30/n \\
\hline Chlamydia & 107 & 50 & $13 / 107$ \\
Gonorrhoea & 31 & 14 & $3 / 31$ \\
HBV & 26 & 12 & $7 / 26$ \\
Chlamydia and gonorrhoea & 14 & 7 & $2 / 14$ \\
HCV & 12 & 6 & $1 / 12$ \\
Syphilis & 11 & 5 & $3 / 11$ \\
HIV & 8 & 4 & $0 / 8$ \\
Chlamydia and HBV & 2 & 1 & $0 / 2$ \\
HIV and syphilis & 1 & 0.5 & $0 / 1$ \\
HIV and syphilis and HCV & 1 & 0.5 & $0 / 1$ \\
Gonorrhoea and HBV & 1 & 0.5 & $1 / 1$ \\
Total & 214 & 100 & $30 / 214$ \\
\hline
\end{tabular}


Table 3 Factors associated with FTR for HIV/STI test results

\begin{tabular}{|c|c|c|c|c|c|c|c|c|}
\hline \multirow[t]{2}{*}{ Factors } & \multirow[t]{2}{*}{ FTR30/n } & \multirow{2}{*}{$\begin{array}{l}\text { FTR } \\
\text { (\%) }\end{array}$} & \multicolumn{3}{|c|}{ Univariate analysis } & \multicolumn{3}{|c|}{ Multivariate analysis* } \\
\hline & & & OR & $95 \% \mathrm{Cl}$ & $P$ value & OR & $95 \% \mathrm{Cl}$ & $P$ value \\
\hline Age (years) and previous HIV testing & & & & & 0.06 & & & 0.01 \\
\hline$\geq 25$ & $16 / 132$ & 12 & 1 & & & 1 & & \\
\hline$<25$ and no previous HIV testing & $1 / 25$ & 4 & 0.30 & $0.04-2.39$ & & 0.31 & $0.03-2.87$ & \\
\hline$<25$ and previous HIV testing & $13 / 57$ & 23 & 2.14 & $0.95-4.81$ & & 3.36 & $1.27-8.84$ & \\
\hline Birthplace & & & & & 0.80 & & & - \\
\hline Metropolitan France & $16 / 120$ & 13 & 1 & & & - & & \\
\hline Sub-Saharan Africa & $8 / 47$ & 17 & 1.33 & $0.53-3.36$ & & - & - & \\
\hline Overseas France or abroad & $6 / 47$ & 13 & 0.95 & $0.35-2.60$ & & - & - & \\
\hline Level of education & & & & & 0.37 & & & - \\
\hline High school graduate & $22 / 170$ & 13 & 1 & & & - & & \\
\hline Not a high school graduate & $8 / 44$ & 18 & 1.49 & $0.62-3.63$ & & - & - & \\
\hline Health insurance coverage & & & & & 0.52 & & & - \\
\hline Statutory health insurance & 24/172 & 14 & 1 & & & - & - & \\
\hline State assistance & $2 / 23$ & 9 & 0.59 & $0.13-2.67$ & & - & - & \\
\hline None & $4 / 19$ & 21 & 1.64 & $0.50-5.37$ & & - & - & \\
\hline Sexual orientation & & & & & 0.08 & & & - \\
\hline MSM & $5 / 76$ & 7 & 1 & & & - & & \\
\hline Heterosexual men & $14 / 77$ & 18 & 3.16 & $1.08-0.25$ & & - & - & \\
\hline Women & $11 / 61$ & 18 & 3.12 & $1.02-9.55$ & & - & - & \\
\hline Occasional partners & & & & & 0.76 & & & - \\
\hline No & $18 / 123$ & 15 & 1 & & & - & & \\
\hline Yes & $12 / 91$ & 13 & 0.89 & $0.40-1.95$ & & - & - & \\
\hline Self-perceived risk of HIV infection ${ }^{* *}$ & & & & & $<0.01$ & & & 0.04 \\
\hline Equal or greater than other people & $7 / 100$ & 7 & 1 & & & 1 & & \\
\hline Less than other people or no risk & $23 / 114$ & 20 & 3.35 & $1.37-8.21$ & & 2.79 & $1.07-7.30$ & \\
\hline Consultation for risk-taking & & & & & 0.21 & & & - \\
\hline No & $13 / 71$ & 18 & 1 & & & - & & \\
\hline Yes & $17 / 143$ & 12 & 0.60 & $0.27-1.32$ & & - & - & \\
\hline Accompanied by another person & & & & & 0.03 & & & 0.01 \\
\hline No & $19 / 169$ & 11 & 1 & & & 1 & & \\
\hline Yes & $11 / 45$ & 24 & 2.55 & $1.11-5.86$ & & 3.45 & $1.36-8.91$ & \\
\hline Anonymous testing & & & & & 0.10 & & & - \\
\hline Yes & $15 / 136$ & 11 & 1 & & & - & & \\
\hline No & $15 / 78$ & 19 & 1.92 & $0.88-4.18$ & & - & - & \\
\hline Participation in SMS programme & & & & & 0.10 & & & - \\
\hline Yes & 18/155 & 12 & 1 & & & - & & \\
\hline No & $12 / 59$ & 20 & 1.94 & $0.87-4.33$ & & - & - & \\
\hline Chlamydia/gonorrhoea testing & & & & & 0.02 & & & $<0.01$ \\
\hline Not tested for chlamydia/gonorrhoea & $10 / 35$ & 29 & 1 & & & 1 & & \\
\hline Chlamydia/gonorrhoea testing with presumptive treatment & $4 / 19$ & 21 & 0.67 & $0.18-2.51$ & & 0.55 & $0.12-2.56$ & \\
\hline Chlamydia/gonorrhoea testing without presumptive treatment & $16 / 160$ & 10 & 0.28 & $0.11-0.68$ & & 0.21 & $0.07-0.59$ & \\
\hline
\end{tabular}

*Variables selected by a stepwise backward selection with a threshold of 0.2 for removal from the model

${ }^{*}$ Compared with the general population 
155 patients who agreed to be notified by SMS, $12 \%$ failed to return whereas this percentage was $20 \%$ among the 59 patients who did not agree, but this difference was not statistically significant (chi2 $p=0.10$ ). The FTR30 rate was not significantly associated with gender, birthplace, educational level, sexual orientation, occasional partners, or testing linked to risk-taking.

Among all factors studied in univariate analyses, the stepwise backward selection retained four factors: age combined with previous HIV testing, self-perceived risk of HIV infection, being accompanied and chlamydia/ gonorrhea testing. In multivariate analysis, patients aged 25 or under who had previously had HIV testing were more likely to fail to return than patients over 25 years old (aOR: 3.36, 95\% CI [1.27-8.84]). A lower selfperceived risk of HIV infection remained significantly associated with a higher FTR30 in multivariate analysis (aOR: $2.79,95 \%$ CI [1.07-7.30]), as well as being accompanied (aOR: 3.45, 95\% CI [1.36-8.91]) compared with patients coming alone. Being tested for chlamydia/gonorrhoea without treatment was associated with a lower FTR30 compared with patients not tested for chlamydia/ gonorrhoea (aOR: 0.21, 95\% CI [0.07-0.59]).

Fifty-two patients were not included in this study as they had not completed the self-administered questionnaire. These patients tended to be older than the study population (proportion of patients $\geq 25$ years was $81 \%$ vs $62 \%$, chi2 $p=0.01$ ). The proportion of women did not differ between included and excluded patients $(29 \%$ vs $17 \%$, chi2 $p=0.10$ ). FTR30 was $17 \%$ among excluded patients and was not significantly different from that observed in the study population $(14 \%$, chi2 $p=0.54)$.

\section{Discussion}

In our centre from October 2016 to May 2017, 14\% of the 214 patients who screened positive for at least one STI and were included in the study failed to return within 30 days. As expected, the FTR within 30 days did not differ from the FTR within 60 days (14 and 11\%, respectively), as the majority of patients returned between 6 and 13 days. One possible limitation of our study is the exclusion of 52 patients out of 266 tested positive (20\%) because they did not complete the selfadministered questionnaire. These excluded patients could have less favourable social characteristics (more often non-French speaking patients, less educated patients not at ease with a written questionnaire). However, examination of the consultation database showed that among patients who were screened positive, the FTR30 rate did not differ significantly between those who were included in the study and those who were not included. The FTR rate differed between HIV (0 FTR) and other STIs (from $1 / 12$ to $7 / 26$ ). As most previous studies on FTR included all patients whatever the result of screening and generally studied only one STI, comparison with our findings must be cautious. Regarding HIV testing, previous studies in similar STI centres reported FTR rates that ranged from 7 to $22 \%[9,12,14]$. The low FTR that we observed among HIV-positive patients is therefore very encouraging. Regarding testing for other STIs, previous studies reported FTR rates that ranged from 5 to $29 \%$ according to the STI tested (chlamydia, hepatitis or syphilis) and the setting [9, 20]. More specifically, FTR rates after chlamydia testing ranged between 17 and 29\% [9, 20]. Despite the limitations we have previously noted, with the exception of HIV our findings thus seem consistent with FTR rates reported in the literature. These findings must be confirmed in larger studies. Nevertheless, they demonstrate the need to take into account all STIs and not only HIV when considering FTR, especially for positive patients.

One approach to decreasing the FTR is to diversify the options for contacting the patient for their results [10, $11,15]$. The option developed in our centre was to propose SMS notification after screening [16]. Although the acceptability of this programme appeared good, this study was not able to demonstrate a statistically significant difference in FTR30 between participants (tested positive for at least one STI) and non-participants in the SMS programme. The impact of SMS notification on failure to return needs to be assessed in a larger sample and diversification of contact options must be pursued to meet the preferences of patients [21-23]. Participation in programmes such as SMS notification may differ according to patients' profiles, such as age and social characteristics [16]. Factors related to the screening structure or screening modalities may affect the decision to undertake STI screening [24, 25]. For instance, patients could also be offered systematic phone calls after testing to reduce the risk of failure in delivering STI screening results [9].

A second approach to decreasing the FTR is to target improvement actions for patients who are at high risk of failure to return for results. In this study, none of the sociodemographic factors analysed was significantly associated with FTR30. However, persons younger than 25 years old who had previous HIV testing were less likely to return for results than others. This was an unexpected finding and several hypotheses could be put forward. One reason could be fear about the results linked to a bad experience during previous testing. Conversely, it is possible that younger persons may think that they do not need to worry about the results because someone will try to contact them if necessary. The higher risk of FTR30 among younger patients with previous HIV testing might also be explained by erroneous beliefs or misconceptions regarding STI risk and prevention, as if STI screening was a protective factor even 
without knowing the result, especially if previous testing was negative. This hypothesis is supported by the results of a French study evaluating trends in HIV-related knowledge, risk perceptions and sexual behaviours that showed an increase in erroneous beliefs regarding HIV transmission between 1994 and 2010 among young adults (18-29 years old) [26]. Moreover, young adults were less convinced of the efficacy of condoms in protecting against HIV (70-80\% in $1992-1994$ vs. $50 \%$ in 2010) and the proportion of respondents who were very afraid of AIDS significantly decreased (from 44 to $20 \%$ ). The decrease in the level of knowledge regarding HIV transmission and prevention over the last decades explains the decrease in adopting prevention practices by young people (condom use, contraception use...) [26]. This demonstrates the need to heighten awareness amongst patients, especially younger ones, during the pre-test counselling on STI prevention and the need to insist that it is imperative to return for results [26].

In this study conducted in 214 patients screened positive for at least one STI, more than half of the patients (53\%) felt that they had a lower risk or no risk of HIV infection compared with the general population. This result highlights the discrepancy between real risk taken and perceived risk. Patients with a lower self-perceived risk of HIV infection were more likely to fail to return for their results. This finding is in agreement with previous studies that reported an association between FTR and a lower perceived risk for HIV [12]. The absence of awareness of risk taken among patients screened positive for STIs is a clear challenge in STIs and HIV prevention, as it affects the probability that these patients will return for their results and thus their chance of being quickly treated and avoiding new infections. It would be of primary importance to investigate this discrepancy and especially the impact of health literacy. This perceived low risk of HIV infection could in fact reflect a lack of knowledge or more precisely a low health literacy regarding STIs [27]. Health literacy represents the degree to which individuals have an understanding of health information in order to make appropriate health decisions $[28,29]$. Patients with low literacy are less likely to understand prevention, treatment and follow-up of STIs and are often at high risk of infection $[28,30]$. Health literacy has also been associated with willingness to comply with healthcare providers' recommendations relative to STIs [27, 29]. Lastly, difficulties in understanding and acting on health information about STIs may negatively influence disease prevention and in particular may increase the likelihood of failure to return for post-test counselling [29]. Moreover, studying the difference in the second category, by differentiating "higher risk" and "equal risk", could provide additional information.
Testing for chlamydia and gonorrhoea without presumptive treatment at the first visit was associated with a lower risk of FTR30 compared with patients not tested for chlamydia/gonorrhoea. Unlike other infections that are screened on a blood sample taken by a nurse, testing for chlamydia and gonorrhoea is based on self-swabbing, making the patient a direct actor in their own screening. Self-swabbing could be an important factor of patient empowerment, as has been suggested in cervical cancer screening [31] and streptococcus testing [32]. In line with these results, the lower FTR30 observed in our study among self-swabbing patients tested for chlamydia and gonorrhoea could reflect a greater empowerment of these patients. This lower risk of FTR30 was not observed for patients presumptively treated. This result was expected as patients believe they are already cured.

The FTR30 in our study was also higher among patients who were accompanied by another person compared with patients who came alone. No data were found in the literature on this factor. A possible hypothesis is that patients who had been motivated to come for screening by their peers may lose the benefit of the group effect when coming back for results, and so are less likely to return.

\section{Conclusion}

In conclusion, factors that affect failure to return (previous HIV testing, self-perceived risk of HIV infection, testing for chlamydia/gonorrhoea and being accompanied) are related to the representations and involvement of the patients in the HIV/STI screening process. They are strongly related to patients' health literacy that directly influences health knowledge, health status, risktaking behaviours and use of health services $[29,30]$.

To decrease failure to return after HIV/STI screening, different approaches could be considered: one approach consists in adapting the screening offer proposed by the centre, another is centred on patients defined as having a high-risk profile. In our study, we tested the impact of SMS notification but this is only one first step to facilitate contact with patients and it is necessary to pursue the diversification of contact options. A profile of patients at high risk of nonreturn was highlighted: all factors associated with FTR30 (previous HIV testing among younger patients, being accompanied, no testing for chlamydia/gonorrhoea, lower self-perceived risk of HIV infection) were related to the representations and involvement of the patient in the STI screening process. Increasing the patients' level of knowledge of STIs and their level of health literacy may be a way to reduce the risk of failure to return for test results and thus to empower patients [28]. 


\section{Abbreviations}

AIDS: Acquired immune deficiency syndrome; aOR: Adjusted odds ratio; Cl: Confidence interval; HBV: Hepatitis B virus; HCV: Hepatitis C virus; HIV: Human immunodeficiency virus; FTR : Failure to return; FTR30: Failure to return within 30 days after testing; MSM: Men who have sex with men; OR : Odds ratio; PrEP : Pre-exposure prophylaxis; POCT : Point-of-care testing; SMS: Short message service; STIs : Sexually transmitted infections; WHO: World health organization

\section{Acknowledgements}

The authors are grateful to Fabienne Vereecke, reception agent at CeGIDD, to the nurses and physicians at CeGIDD for their help during the study, and to the patients for their participation. The authors wish to thank Frédéric Legrais and Christelle Duteil for their contributions to data acquisition and management. We also thank Nina Crowte for her assistance in reviewing the language of the manuscript.

\section{Authors' contributions}

CR: data management, analysis, writing and revisions. ELR: design, analysis, writing and manuscript review. PP: design and manuscript review. MS: study concept and manuscript review. CS: study concept and manuscript review. PT: study concept, design, analysis, writing and manuscript review. All authors read and approved the final manuscript.

\section{Funding}

Not applicable.

\section{Availability of data and materials}

The datasets analysed during the current study are not publicly available due to patient confidentiality but are available from the corresponding author after having fulfilled French legal mandatory declarations to access hospital private data.

\section{Ethics approval and consent to participate}

This study is based on patients' medical records, including a selfadministered questionnaire. Use of these data for research received institutional review board approval from the French Data Protection Authority (authorization CNIL no. 2005208 v0). Patients are informed in the welcome booklet and by poster in the centre of their right to object to the use of their data for research purposes. Moreover, this study has been declared to the AP-HP (Paris hospitals) Data Protection Office (no. 20190402105757).

\section{Consent for publication}

Not applicable.

\section{Competing interests}

The authors declare that they have no competing interests.

\section{Author details}

${ }^{1}$ Department of Public Health, University Hospital

Saint-Louis-Lariboisière-Fernand-Widal, AP-HP, 200 rue du

Faubourg-Saint-Denis, F-75475, Paris Cedex 10, Paris, France. ${ }^{2}$ Free Sexual Health Centre, University Hospital Saint-Louis-Lariboisière-Fernand-Widal, AP-HP, Paris, France. ${ }^{3}$ Institut National d'Etudes Démographiques (Ined), Aubervilliers, France. ${ }^{4}$ University Paris-Saclay, University Paris-Sud, UVSQ, CESP, INSERM, Paris, Villejuif, France.

Received: 25 July 2019 Accepted: 16 October 2020

\section{Published online: 27 October 2020}

\section{References}

1. Unemo M, Bradshaw CS, Hocking JS, de Vries HJC, Francis SC, Mabey D, Marrazzo JM, Sonder GJB, Schwebke JR, Hoornenborg E, et al. Sexually transmitted infections: challenges ahead. Lancet Infect Dis. 2017;17(8): e235-79.

2. WHO. Global health sector strategy on sexually transmitted infections 20162021: towards ending STIs. Geneva, Switzerland: WHO; 2016.

3. Sullivan PS, Lansky A, Drake A, Investigators H. Failure to return for HIV test results among persons at high risk for HIV infection: results from a multistate interview project. J Acquir Immune Defic Syndr. 2004;35(5):511-8.
4. Ngangue P, Bedard E, Ngueta G, Adiogo D, Gagnon MP. Failure to return for posttest counseling and HIV test results at the prevention and voluntary testing and counseling centers of Douala, Cameroon: an evaluation of a routine five-year program. AIDS Res Treatment. 2016:7. Article ID 9720148. https://doi.org/10.1155/2016/9720148.

5. Defo D, Kouotou EA, Nansseu JR. Failure to return to receive HIV-test results: the Cameroon experience. BMC Res Notes. 2017;10(1):309.

6. Wong D, Berman SM, Furness BW, Gunn RA, Taylor M, Peterman TA. Time to treatment for women with chlamydial or gonococcal infections: a comparative evaluation of sexually transmitted disease clinics in 3 US cities. Sex Transm Dis. 2005;32(3):194-8.

7. Hong NT, Wolfe MI, Dat TT, McFarland DA, Kamb ML, Thang NT, Thai HN, Del Rio C. Utilization of HIV voluntary counseling and testing in Vietnam: an evaluation of 5 years of routine program data for national response. AIDS Educ Prev. 2011;23(3 Suppl):30-48.

8. Sesay C, Chien LY. Analysis of factors associated with failure to return for an HIV-test result in the Gambia. Afr J AIDS Res (AJAR). 2012;11(2):83-9.

9. Prazuck T, Ducasse E, Huard E, Languille A, Sandberg F, Guinard J, Theillay E, Hocqueloux L. Rapid tests for the diagnosis of HIV infection in free and anonymous screening consultations in France: consequences on concomitant serologies feedback and usefulness of recalling patients lost to follow-up. Bull Epidemiol Hebd. 2013;30:369-76.

10. Bailey S, Scalley B, Gilles M. Text 2 treat - using SMS to recall clients for treatment. Int J STD AIDS. 2014;25(14):1038-40.

11. Rodriguez-Hart C, Gray I, Kampert K, White M, Wolfe C, Wilson M, Cooksey A. Just text me! Texting sexually transmitted disease clients their test results in Florida, February 2012-January 2013. Sex Transm Dis. 2015;42(3):162-7.

12. Laanani M, Dozol A, Meyer L, David S, Camara S, Segouin C, Troude P. Factors associated with failure to return for HIV test results in a free and anonymous screening Centre. Int J STD AIDS. 2015;26(8):549-55.

13. Beymer MR, DeVost MA, Weiss RE, Dierst-Davies R, Shover CL, Landovitz RJ, Beniasians C, Talan AJ, Flynn RP, Krysiak R, et al. Does HIV pre-exposure prophylaxis use lead to a higher incidence of sexually transmitted infections? A case-crossover study of men who have sex with men in Los Angeles, California. Sex Transm Infect. 2018;94(6):457-62.

14. Pahlavan G, Burdet C, Laouenan C, Guiroy F, Bouscarat F, Tosini W, Yazdanpanah Y, Bouvet E. Predictors of return rate for an HIV-positive result in a French voluntary counseling and testing Centre. Int J STD AIDS. 2015; 26(1):33-6.

15. Desai M, Woodhall SC, Nardone A, Burns F, Mercey D, Gilson R. Active recall to increase HIV and STI testing: a systematic review. Sex Transm Infect. 2015 91(5):314-23.

16. Troude P, Segouin C, Duteil C, Shelly M, de La Rochebrochard E. Text messaging after HIV and sexually transmitted infection screening: do patients' profiles matter? Sex Transm Dis. 2019;46(3):159-64.

17. Bell SA, Delpech V, Casabona J, Tsereteli N, de Wit J. Delivery of HIV test results, post-test discussion and referral in health care settings: a review of guidance for European countries. HIV Med. 2015;16(10):620-7.

18. Hightow LB, Miller WC, Leone PA, Wohl D, Smurzynski M, Kaplan AH. Failure to return for HIV posttest counseling in an STD clinic population. AIDS Educ Prev. 2003;15(3):282-90.

19. Kinsler JJ, Cunningham WE, Davis C, Wong MD. Time trends in failure to return for HIV test results. Sex Transm Dis. 2007;34(6):397-400.

20. McClean H, Carne C, Bunting P, Bhaduri S, Fernandes A, Dhar J, Estreich S, Daniels D. National audit group of the British association for sexual health and HIV: UK National Audit of chlamydial infection management in sexual health clinics. Case notes audit: information-giving, partner notification and follow-up. Int J STD AIDS. 2008;19(7):473-6.

21. Labacher $L$, Mitchell C. Talk or text to tell? How young adults in Canada and South Africa prefer to receive STI results, counseling, and treatment updates in a wireless world. J Health Commun. 2013;18(12):1465-76.

22. Sharma A, Stephenson RB, White D, Sullivan PS. Acceptability and intended usage preferences for six HIV testing options among internet-using men who have sex with men. SpringerPlus. 2014;3:109.

23. Yang M, Prestage G, Maycock B, Brown G, de Wit J, McKechnie M, Guy R, Keen P, Fairley CK, Zablotska IB. The acceptability of different HIV testing approaches: cross-sectional study among GMSM in Australia. Sex Transm Infect. 2014;90(8):592-5.

24. Spielberg F, Kurth A, Gorbach PM, Goldbaum G. Moving from apprehension to action: HIV counseling and testing preferences in three at-risk populations. AIDS Educ Prev. 2001;13(6):524-40. 
25. Bilardi JE, Walker S, Read T, Prestage G, Chen MY, Guy R, Bradshaw C, Fairley CK. Gay and bisexual men's views on rapid self-testing for HIV. AIDS Behav. 2013;17(6):2093-9.

26. Beltzer N, Saboni L, Sauvage C, Lydie N, Semaille C, Warszawski J, Group KF. An 18-year follow-up of HIV knowledge, risk perception, and practices in young adults. AIDS. 2013;27(6):1011-9.

27. Barragan M, Hicks G, Williams MV, Franco-Paredes C, Duffus W, del Rio C. Low health literacy is associated with HIV test acceptance. J Gen Intern Med. 2005;20(5):422-5.

28. Fortenberry JD, McFarlane MM, Hennessy M, Bull SS, Grimley DM, St Lawrence J, Stoner BP, VanDevanter N. Relation of health literacy to gonorrhoea related care. Sex Transm Infect. 2001;77(3):206-11.

29. Hicks G, Barragan M, Franco-Paredes C, Williams MV, del Rio C. Health literacy is a predictor of HIV/AIDS knowledge. Fam Med. 2006;38(10):717-23.

30. Baker DW. Reading between the lines: deciphering the connections between literacy and health. J Gen Intern Med. 1999;14(5):315-7.

31. Franco EL. Self-sampling for cervical cancer screening: empowering women to lead a paradigm change in cancer control. Curr Oncol. 2018;25(1):e1-3.

32. Murray MA, Schulz LA, Furst JW, Homme JH, Jenkins SM, Uhl JR, Patel R, Cockerill FC, Myers JF, Pritt BS. Equal performance of self-collected and health care worker-collected pharyngeal swabs for group a streptococcus testing by PCR. J Clin Microbiol. 2015:53(2):573-8.

\section{Publisher's Note}

Springer Nature remains neutral with regard to jurisdictional claims in published maps and institutional affiliations.

Ready to submit your research? Choose BMC and benefit from:

- fast, convenient online submission

- thorough peer review by experienced researchers in your field

- rapid publication on acceptance

- support for research data, including large and complex data types

- gold Open Access which fosters wider collaboration and increased citations

- maximum visibility for your research: over $100 \mathrm{M}$ website views per year

At BMC, research is always in progress.

Learn more biomedcentral.com/submissions 